\title{
Antifungal Activity of a Plant Cystatin
}

\author{
Mónica Pernas, Emilia López-Solanilla, Rosa Sánchez-Monge, Gabriel Salcedo, \\ and Pablo Rodríguez-Palenzuela \\ Department of Biotechnology, E.T.S. Ingenieros Agrónomos, Universidad Politécnica de Madrid, \\ Ciudad Universitaria, 28040 Madrid, Spain \\ Accepted 23 March 1999.
}

Purified chestnut cystatin inhibited the growth of the phytopathogenic fungi Botrytis cinerea, Colletotrichum graminicola, and Septoria nodorum, but not that of the saprophyte Trichoderma viride. Furthermore, the cystatin strongly affected the protease activity of $B$. cinerea but had no effect on the protease activity of $T$. viride. These results suggest that chestnut cystatin contributes to plant defense against phytopathogenic fungi.

Cystatins are proteinaceous inhibitors of cystein proteases identified in animals (Anastasi et al. 1983), as well as in monocotiledoneous (Abe et al. 1987; Kondo et al. 1990; Abe et al. 1992) and dicotiledoneous plants (Zhao et al. 1996; Misaka et al. 1996). Most plant cystatins are 12 to $16 \mathrm{kDa}$ in size, contain no disulfide bonds, and show sequence homology with the family 2 of animal cystatins, which includes egg cystatin (Barret 1987). However, phytocystatins have been recently grouped into a specific subfamily apart from their animal homologs (Margis et al. 1998). Two possible roles have been proposed for these plant inhibitors: (i) they are thought to act as regulators of proteolysis during seed maturation and germination (Salmia 1980; Abe et al. 1992); and (ii) they could contribute to plant defense by inhibiting exogenous proteases, such as those from insect pests and nematodes (Zhao et al. 1996; Urwin et al. 1995). In fact, several cystatins can inhibit in vitro digestive proteases from coleopteran insects (Hines et al. 1991; Liang et al. 1991; Zhao et al. 1996), and transgenic plants overexpressing cystatins and showing enhanced resistance against insects (Leplé et al. 1995) and nematodes (Urwin et al. 1995, 1997) have been reported. In contrast, no data have been reported on their toxic activity against phytopathogenic fungi and bacteria.

In this work, we have tested the toxic properties of a recently characterized cystatin from chestnut (Pernas et al. 1998) against certain species of phytopathogenic fungi and bacteria. The recombinant inhibitor, which has been proved to be identical to that found in chestnut seeds, was isolated as reported by Pernas et al. (1998). This purified cystatin was evaluated for its effect on the growth of three phytopathogenic

Corresponding author: P. Rodríguez-Palenzuela

E-mail: pablo@bit.etsia.upm.es

Mónica Pernas and Emilia López-Solanilla have contributed equally to this work. fungi, Botrytis cinerea, Colletotrichum graminicola, and Septoria nodorum, and the saprophyte Trichoderma viride, as well as two phytopathogenic bacteria, Erwinia chrysanthemi and Clavibacter michiganense. The in vitro inhibition assays were performed by the method described by Broekaert et al. (1990), slightly modified as described by Molina et al. (1993).

The chestnut cystatin did not exert antibacterial activity toward the two phytopathogenic species tested (up to a $9 \mu \mathrm{M}$ concentration of inhibitor per assay). By contrast, the purified protein fully inhibited the growth of three of the fungi tested (B. cinerea, C. graminicola, and $S$. nodorum), with a similar inhibitor concentration $(100 \mu \mathrm{g} / \mathrm{ml} \approx 9 \mu \mathrm{M}$; see Figure 1$)$, whereas the nonphytopathogenic fungus $T$. viride was not affected at this protein level. Interestingly, two other cysteinproteinase inhibitors, egg cystatin and E-64 (the nonprotein diagnostic inhibitor of this class of proteolytic enzymes), did not show any inhibitory effect in the same antifungal tests (Fig. 1 and data not shown for E-64). Moreover, soybean Kunitz and Bowman-Birk inhibitors of trypsin-like and trypsin/chymotrypsin-like proteases, respectively, also failed to inhibit the growth of the four fungi assayed, when similar protein concentrations were used (not shown). Wheat thionin was also included as a positive control in all antifungal assays, because of its well-known antipathogenic activity (reviewed by García-Olmedo et al., in press). The toxic effects that chestnut cystatin exerts on the growth of $B$. cinerea, $C$. graminicola, and $S$. nodorum were monitored by microscopical observation $24 \mathrm{~h}$ after the addition of the protein. Figure 2 shows that the mycelial growth was strongly diminished at $100 \mu \mathrm{g} / \mathrm{ml}$, and some effect is also visible at $25 \mu \mathrm{g}$ of inhibitor per ml. Spore germination of $C$. graminicola was completely inhibited at the highest concentration. In addition, morphological changes, such as hyphal shortening and wall thickening, were observed for $B$. cinerea and $C$. graminicola, although these alterations were not apparent in $S$. nodorum.

These results clearly indicate that the chestnut cystatin has antifungal activity at the micromolar level that is comparable to that of thionin and many antibiotics. In contrast to thionin, chestnut cystatin appears to act selectively against certain fungi and had no effect against the bacteria tested. Lorito et al. (1994) reported the in vitro toxicity of trypsin and chymotrypsin inhibitors from cabbage against $B$. cinerea, although the concentration needed for a complete growth inhibition $(>600$ $\mu \mathrm{g} / \mathrm{ml})$ is around 10 times higher than that needed of chestnut cystatin against the same fungus. In our assays, we found that 
the Bowman-Birk and Kunitz inhibitors were not active at 100 $\mu \mathrm{g} / \mathrm{ml}$ toward any of the fungi tested, although higher concentrations were not tested. Interestingly, the two widely used inhibitors of cysteine protease, E64 and egg cystatin, had no effect on the growth of all the organisms assayed. Two hy- potheses could explain this fact: (i) evolution of cystatins to their potential targets may have occurred, leading to specificity between chestnut cystatin and the proteases of its potential pathogens; or (ii) the toxic effect of the chestnut cystatin could be due to another biological activity of this molecule, not di-

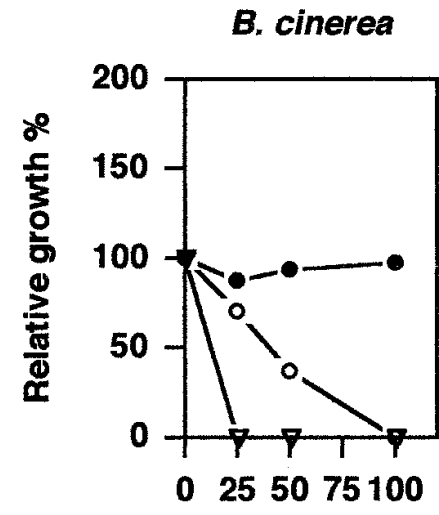

$\mu \mathrm{g} / \mathrm{ml}$
C. graminicola

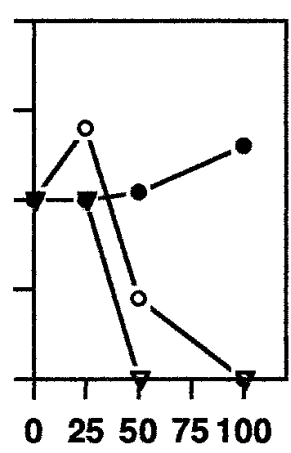

$\mu \mathrm{g} / \mathrm{ml}$
S. nodorum

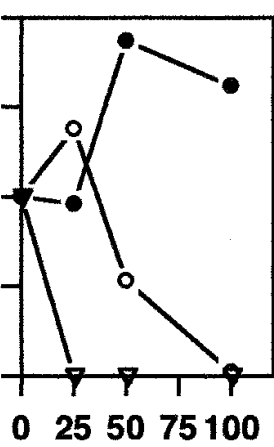

$\mu \mathrm{g} / \mathrm{ml}$
T. viride

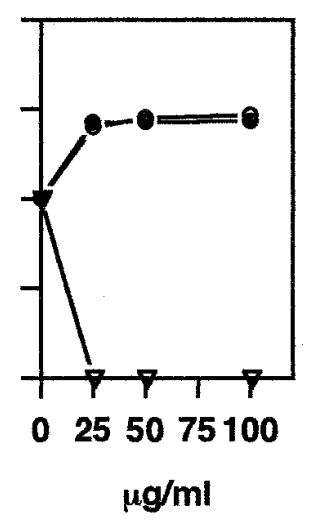

Fig. 1. Effects on the growth of Botrytis cinerea, Colletotrichum graminicola, Septoria nodorum, and Trichoderma viride, of chestnut cystatin (open circles), egg cystatin (closed circles), and thionin (triangles). The bioassay consisted of incubating $10^{3}$ spores in $100 \mu$ of $1 / 3 \times$ potato dextrose broth at $25^{\circ} \mathrm{C}, 48 \mathrm{~h}$, in the presence of different inhibitor concentrations. Growth was monitored by measuring absorbance at $492 \mathrm{~nm}$, and expressed as a percentage of growth in the absence of the inhibitory agent. Results are for a typical experiment from three independent trials and the magnitude of standard errors was smaller than the symbols in all cases $(<5 \%)$.

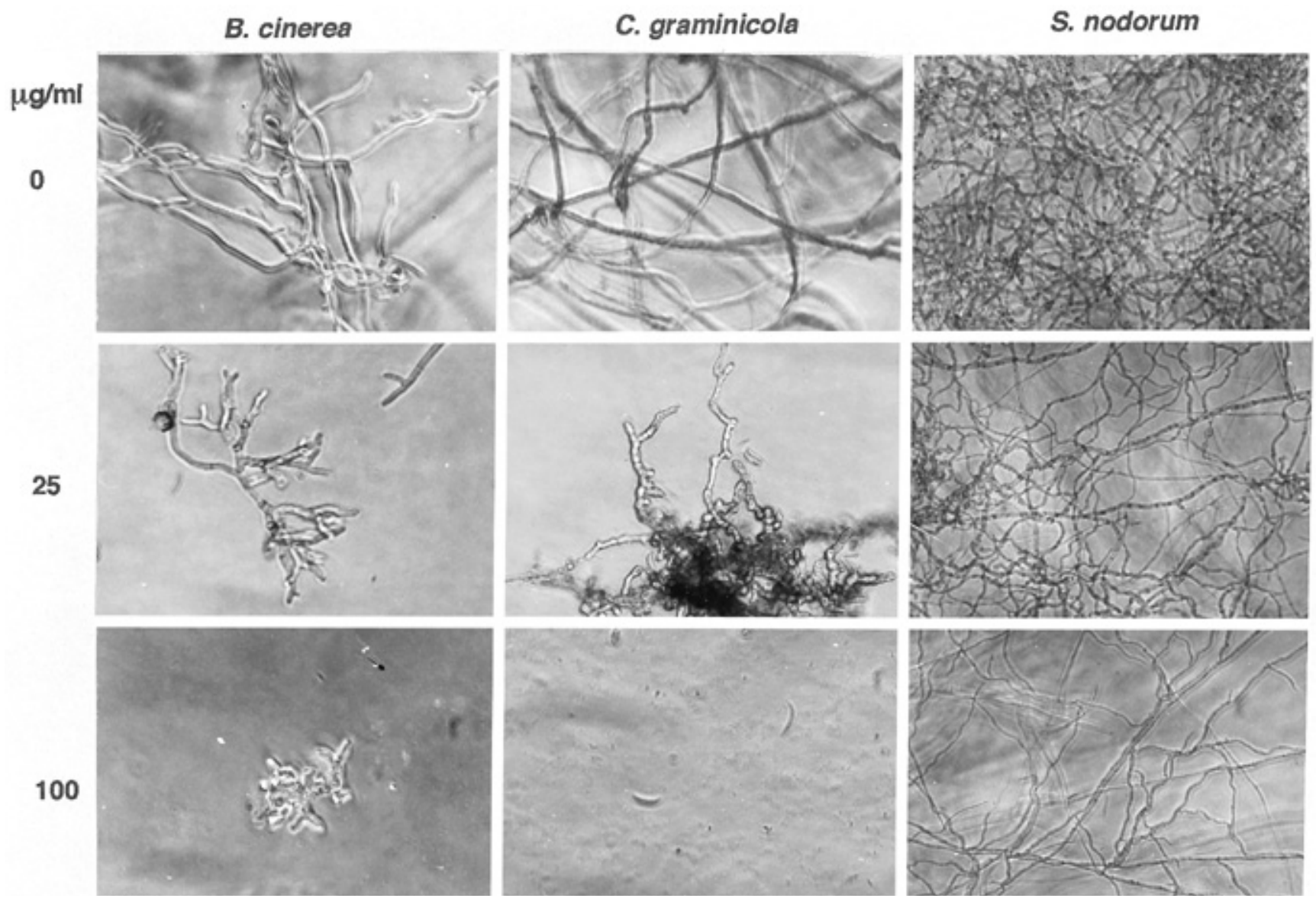

Fig. 2. Morphological changes and growth arrest of Botrytis cinerea, Colletotrichum graminicola, and Septoria nodorum observed at indicated concentrations of chestnut cystatin. Incubation was performed under same conditions described in Figure 1. Microscopical photographs $(\times 300)$ were taken at $24 \mathrm{~h}$. 
rectly related to its inhibitory properties. As a preliminary test of the first hypothesis, mycelial protein extracts of $B$. cinerea (sensitive) and $T$. viride (nonsensitive) were obtained, the total protease activity of the extracts was determined (Twining, 1984), and, subsequently, a protease inhibition assay was performed as described (Pernas et al. 1998). As shown in Table 1, the chestnut cystatin clearly inhibited the total protease activity of $B$. cinerea, whereas it had no effect on the proteases from $T$. viride. In the same assay, egg cystatin, E-64, and the soybean Bowman-Birk trypsin inhibitor had little or no effect on the protease activity of both fungal extracts. The lack of inhibition by E-64 could suggest a strong divergence of the $B$. cinerea proteinases affected by chestnut cystatin with respect to the typical enzymes of the papain family. This is the case with several cysteine proteases from animal, bacterial, or plant origin that are very weakly inhibited, or not inhibited, by E-64 (Barret et al. 1982; Kamens et al. 1996; Harrach et al. 1998).

The fact that chestnut cystatin causes growth arrest and protease inhibition in the phytopathogenic fungus $B$. cinerea, but none of these effects in the saprophyte fungus $T$. viride, suggests that both phenomena are related and probably have biological relevance in plant defense against pathogens. However, it is not clear where the interaction between the cystatin and its putative target takes place. Different scenarios could be considered: (i) the cystatin could act on extracellular fungal proteases, since this type of protease has been identified as secreted proteins (Impoolsup et al. 1981); (ii) the target could be located in the fungal cell wall or in the plasmatic membrane; or (iii) the cystatin could reach the cytoplasm, as has been suggested to explain the mode of action of oryzacystatins on Vero cells (Kondo et al. 1992). A possible link between fungal toxicity and protease inhibition relies on the fact that a protease activity (which has been claimed to be of the cysteine type) is required for the processing of the membrane-bound chitin synthase precursor (Georgopapadakou and Smith 1985; Machida and Saito 1993). Thus, the observed effects of chestnut cystatin on fungal growth could be related to its indirect inhibition of fungal cell wall development.

In conclusion, our data indicate that chestnut cystatin shows a strong antifungal activity on several phytopathogenic fungi, which is probably related to its inhibitory activity against fungal proteases. This is the first report of such activity for this protein family, and suggests a role in plant protection of this inhibitor toward fungal pathogens. At the same time, these results point to the fact that fungal cysteine proteases are potential targets for the development of new fungicides.

Table 1. Inhibition of the total protease activity of Botrytis cinerea and Trichoderma viride by chestnut cystatin (CsC), egg cystatin (CEW), E64, and Bowman-Birk (BB) inhibitors

\begin{tabular}{lccc}
\hline & & \multicolumn{2}{c}{ Inhibition $(\%)^{\mathbf{a}}$} \\
\cline { 3 - 4 } Inhibitor & $\boldsymbol{\mu M}$ /assay & $\boldsymbol{B}$. cinerea & T. viride \\
\hline CsC & 2.5 & $43 \pm 1$ & - \\
CsC & 5 & $56 \pm 1$ & - \\
CEW & 5 & $17 \pm 1$ & - \\
E-64 & 5 & - & - \\
BB & 5 & $10 \pm 1$ & -
\end{tabular}

a Values are means \pm SE ( $n=4$, two independent experiments); -: no inhibition.

\section{ACKNOWLEDGMENTS}

We thank Antonio Molina and Rosa Raposo for the generous gift of fungal spores and Joaquín García for technical assistance. Financial support was from MEC (grant PB95-0035) and from CAM (grant M97 021002).

\section{LITERATURE CITED}

Abe, K., Emory, Y., Kondo, H., Suzuki, K., and Arai, S. 1987. Molecular cloning of a cysteine proteinase inhibitor of rice (Oryzacystatin). J. Biol. Chem. 26:16793-16797.

Abe, M., Abe, K., Kuroda, M., and Arai, S. 1992. Corn kernel cysteine proteinase inhibitor as a novel cystatin superfamily member of plant origin. Eur. J. Biochem. 209:933-937.

Anastasi, A., Brown, M. A., Kembhavi, A. A., Nicklin, M., Sayers, C., Sunter, D., and Barret, A. J. 1983. Cystatin, a protein inhibitor of cysteine proteinases. Biochem. J. 211:129-138.

Barret, A. 1987. The cystatins: A new class of peptidase inhibitors. Trends Biochem. Sci. 12:193-196.

Barret, A. J., Khembhavi, A. A., Brown, M. A., Kirschke, H., Knight, C. G., Tamai, M, and Hanada, K. 1982. L-trans-epoxysuccinyl-leucylamido(4-guanidino)butane (E-64) and its analogues as inhibitors of cysteine proteinases including cathepsins B, H and L. Biochem. J. 20:189-198.

Broekaert, W. F., Terras, F. R. G., Cammue, B. P. A., and Vanderleyden, J. 1990. An automated quantitative assay for fungal growth. FEMS Microbiol. Lett. 69:55-60.

García-Olmedo, F., Molina, A., Alamillo, J. M., and RodriguezPalenzuela, P. Plant defense peptides. Byopolymers-Peptide Sci. (In press.)

Georgopapadakou, N., and Smith, S. 1985. Chitin synthase in Candida albicans: Comparison of digitonin-permeabilized cells and spheroplast membranes. J. Bacteriol. 162:826-829.

Harrach, T., Eckert, K., Maurer, H. R, Machleidt, I., Machleidt, W., and Nuck, R. 1998. Isolation and characterization of two forms of an acidic bromelain stem proteinase. J. Protein Chem. 17:351-361.

Hines, M. E., Osuala, C. I., and Nielsen, S. S. 1991. Isolation and partial characterization of a soybean cystatin cysteine proteinase inhibitor of coleopteran digestive proteolytic activity. J. Agric. Food Chem. 39: $1515-1520$.

Impoolsup, A., Bhumiratana, A., and Flegel, T. W. 1981. Isolation of alkaline and neutral proteases from Aspergillus flavus var. columnaris, a soy sauce Koji mold. Appl. Environ. Microbiol. 42:619-628.

Kamens, J., Paskind, M., Hugumin, M., Talanian, R. V., Allen, H., Banach, D., Bump, N., Johnston, C. G., Li, P., Mankovich, J. A., Terranova, M., and Ghayur, T. 1996. Identification and characterization of $\mathrm{ICH}-2$, a novel member of the interleukin-1 $\beta$-converting enzyme family of cysteine proteases. J. Biol. Chem. 270:15250-15266.

Kondo, H., Abe, K., Nishimura, I., Watanabe, H., Emory, Y., and Arai, S. 1990. Two distinct cystatin species in rice seeds with different specificities against cysteine proteinases. J. Biol. Chem. 265:1583215837.

Kondo, H., Ijiri, S., Abe, K., Maeda, H., and Arai, S. 1992. Inhibitory effect of oryzacystatins and a truncation mutant on the replication of poliovirus in infected Vero cells. FEBS Lett. 299:48-50.

Leplé, J. C., Bonad-Bottino, M., Augustin, S., Pilate, G., Dumanois, V., Delplanque, A., Cornu, D., and Jouanin, L. 1995. Toxicity to Chrysomela tremulae (Coleoptera: Chrysomelidae) of transgenic poplars expressing a cysteine proteinase inhibitor. Mol. Breeding 1:319-328.

Liang, C., Brookhart, G., Feng, G. H., Reeck, G. R., and Kramer, K. J. 1991. Inhibition of digestive proteinases of stored grain coleoptera by oryzacystatin, a cysteine proteinase inhibitor from rice seed. FEBS Lett. 2:139-142.

Lorito, M., Broadway, R. M., Hayes, C. K., Woo, S. L., Noviello, C., Williams, D. L., and Harman, G. E. 1994. Proteinase inhibitors from plants as a novel class of fungicides. Mol. Plant-Microbe Interact. 7: 525-527.

Machida, S., and Saito, M. 1993. Purification and characterization of membrane-bound chitin synthase. J. Biol. Chem. 268:1702-1707.

Margis, R., Reis, E. M., and Villeret, V. 1998. Structural and phylogenetic relationships among plant and animal cystatins. Arch. Biochem. Biophys. 359:24-30. 
Misaka, T., Kuroda, M., Iwabuchi, K., Abe, K., and Arai, S. 1996. Soyacystatin, a novel cysteine proteinase inhibitor in soybean, is distinct in protein structure and gene organization from other cystatins of animal and plant origin. Eur. J. Biochem. 240:609-614.

Molina, M., Ahl Goy, P., Fraile, A., Sánchez-Monge, R., and GarcíaOlmedo, F. 1993. Inhibition of bacterial and fungal plant pathogens by thionins of types I and II. Plant Sci. 92:169-177.

Pernas, M., Sánchez-Monge, R., Gómez, L., and Salcedo, G. 1998. A chestnut seed cystatin differentially effective against cysteine proteinases from closely related pests. Plant Mol. Biol. 38:1235-1242.

Salmia, M. 1980. Inhibitors of endogenous proteinases in Scots pine seed: Fractionation and activity changes during germination. Physiol. Plant. 48:266-270.
Twining, S. S. 1984. Fluorescein isothiocyanate-labeled casein assay for proteolytic enzymes. Anal. Biochem. 143:30-34.

Urwin, P. E., Atkinson, H. J., Waller, D. A., McPherson, M. J. 1995. Engineered oryzacystatin-I expressed in transgenic hairy roots confers resistance to Globodera pallida. Plant J. 8:121-131.

Urwin, P. E., Lilley, C. J., McPherson, J., and Atkinson, J. 1997. Resistance to both cyst and root-knot nematodes conferred by transgenic Arabidopsis expressing a modified plant cystatin. Plant J. 12:455-461.

Zhao, Y., Botella, M. A., Subramanian, L., Niu, X., Nielsen, S. S., Bressan, R. A., and Hasegawa, P. M. 1996. Two wound inducible soybean cysteine proteinase inhibitors have greater insect digestive proteinase inhibitory activities than a constitutive homolog. Plant Physiol. 111: 1299-1306 